\title{
Analysis of the characteristics in variation of groundwater level in consideration of geological property during excavation in urban area
}

\author{
Woo-Seok Kim, a , Jang- Hwan Cha ${ }^{2, b}$, Oil Kwon ${ }^{1, c}$, Yong Baek ${ }^{3, d}$, \\ Jae-Yong Lee Le $^{2, e}$
}
${ }^{1}$ Geotechnical Engineering Research Institute, Korea Institute of Civil Engineering and Building, Gyeonggi-Do, 10223, Republic of Korea
${ }^{2}$ Infra Research Institute, INCITY CO., LTD., Seoul, 06184, Republic of Korea
${ }^{3}$ Multi Disaster Countermeasure Organization, Korea Institute of Civil Engineering and Building, Gyeonggi-Do, 10223, Republic of Korea

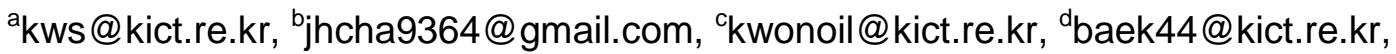 ejylee@incity.co.kr

Keywords: Land Subsidence, Groundwater, Ground Deformation, Saturated/Unsaturated

\begin{abstract}
The scale and depth of excavation necessary for building the structure has been increased in line with concentrated urbanization and the effect on underground structure by varying groundwater level is also increasingly growing, which require advanced ground deformation prediction technology depending on variation of groundwater level. Particularly, as unconsolidated sediment or soil repeats saturated-unsaturated cycle, volumetric water content in voids of soil varies accordingly. In this study, a complete grid-base groundwater flow analysis model which combines the 3D groundwater analysis module for saturated and unsaturated zone was used. To evaluate the applicability of the model used, modeling was conducted on assumption of the scenario. In particular, a conceptual model incorporating the rock mass and geological structure that shall be considered in predicting the groundwater behavior and ground deformation by excavation was adopted.
\end{abstract}

\section{Introduction}

Development of underground space has been increasingly expanding amid the space above the ground is getting saturated in the wake of concentrated development in urban area. Accordingly excavation scale and depth are increased and underground structure is enlarged which causes the effect by varying groundwater level to grow. Thus, prediction of ground deformation in relation to variation of groundwater level resulting from excavation is more than important [1].

The study is intended to analyze the groundwater behavior in saturated and unsaturated ground in consideration of ground excavation and the change to hydraulic conditions so as to develop the physical-based 3D finite element analysis model that will be able to quantitatively predict the land subsidence [2]. Given the saturated and unsaturated condition are repeated because of rain and excavation which results in variation to volumetric water content in void of soil media and thus predicting the ground deformation such as land subsidence would be possible in a way of predicting the soil porosity or effective porosity [3].

It's intended to develop the saturated/unsaturated 3D groundwater flow analysis module before developing the integrated analysis model. Particularly it's aimed at establishing the geological element model through the analysis of groundwater level variation characteristics depending on type of rock and geological structure, which will be incorporated into the groundwater flow analysis module to be developed $[4,5]$.

\section{The Model to Predict the Groundwater Variation by Excavation}

As saturated-unsaturated condition of Unconsolidated soil or clayey soil by torrential rain or excavation is repeated, change to volumetric water content in soil void is occurred and thus ground 
settlement based on prediction of effective porosity depending on groundwater behavior becomes predictable.

Particularly, prediction of groundwater behavior in saturated - unsaturated condition of the ground shall be preceded in order to predict variation of the effect by groundwater level during excavation and ground deformation comprehensively as well and the model which quantitatively predicts the volumetric change of the ground shall be established by simulating the water content of soil dynamically. Hence, a complete grid-based groundwater flow analysis model (SEEFLOW3D: SEEpage FLOW model for 3D saturated-unsaturated porous media) in which 3D groundwater analysis module for saturated and unsaturated zone is dynamically combined is used [5].

\section{Evaluation of Model Applicability}

To evaluate the applicability of the developed model, modeling is conducted using the excavation scenarios by geological characteristic which is divided into the rock and unconsolidated sediments (or soil, hereinafter called soil). And the rock mass is classified into igneous rock, sedimentary rock and metamorphic rock and the rock. Soil is classified into various kinds according to unified soil classification system (USCS) and geological structure is classified into the fault, fold, disconformity and lineation. In this study, a conceptual model incorporating the bedrock and geological structure which are considered the objects in predicting the groundwater flow and ground deformation is set as major characteristic factor.

The scenario depending on excavation is divided into ground excavation (Case 1) by depth (10m, 20m) and cavity excavation at the zone where the fault zone exists (Case 2) (Fig. 1) and flow analysis is reviewed.

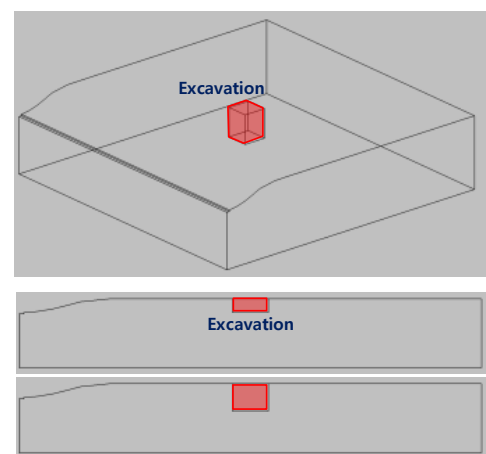

(a)

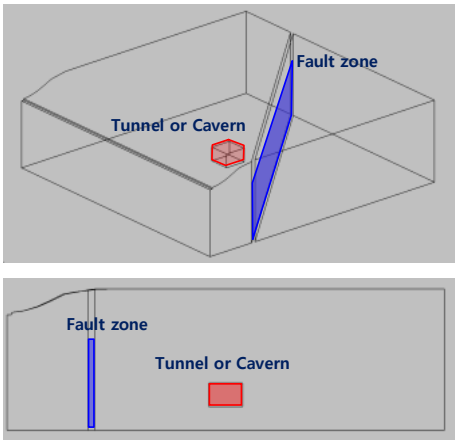

(b)

Fig. 1 Ground excavation scenario considering the geological characteristics:

(a) Excavation by depth (Case 1), (b) cavity excavation when fault zone exists (Case 2).

\section{Conceptual Model Incorporating the Rock Type and Geological Structure}

Conceptual model is set based on ground excavation scenario in consideration of geological characteristics, geological structure, river and rainfall. Case 1 model zone is set as $1,000 \mathrm{~m}$ (east-west) $x$ 1,000m (south-north) x 50m (thickness) and the height, EL (-) 15 35m and excavation zone is set as $40 \mathrm{~m}$ (east-west) $\mathrm{x} 40 \mathrm{~m}$ (south-north) $\mathrm{x} 10 \mathrm{~m}$ (thickness) and 40m (east-west) $\mathrm{x} 40 \mathrm{~m}$ (south-north) x 20m (thickness) and the zone for excavating $10 \mathrm{~m}$ and $20 \mathrm{~m}$ is set differently (Fig. 2)

And the bed is divided into 10 beds and Case 1 comprises mostly the soil and geological characteristics are represented by silty sand, gravely sand and weathered rock.

The grid of Case 1 was separated into 47,776 nodes and 87,474 prisms before excavation and node and prism in excavation zone were eliminated to simulate the effect by excavation. Thus $10 \mathrm{~m}$ excavation comprises of 47,242 nodes and 86,178 prisms while 20m excavation comprises of 46,886 nodes and 85,314 prisms. Model zone in Case 2 is set as $1,000 \mathrm{~m}$ (east-west) x 1,000m (south-north) x 60m (thickness) and the height, EL (-) 25 35m.

When it comes to excavation zone, it's set as $40 \mathrm{~m}$ (east-west) $\mathrm{x} 40 \mathrm{~m}$ (south-north) $\mathrm{x} 10 \mathrm{~m}$ (thickness) at 40m depth in center of the model (Fig. 3) When it comes to the bed, bedrock was 
considered on assumption of cavity excavation (Case 2) and geological characteristics were represented by silty sand, weathered rock and hard rock and a $10 \mathrm{~m}$ wide vertical fault zone was set diagonally $100 \mathrm{~m}$ to the northeast from the underground cavity.

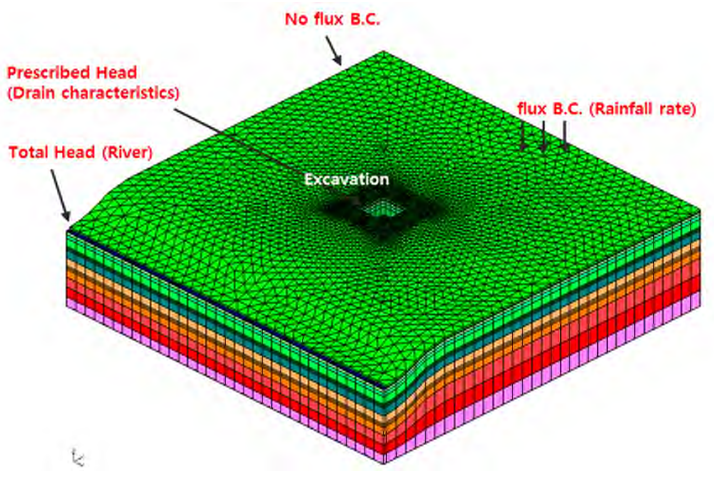

(a)

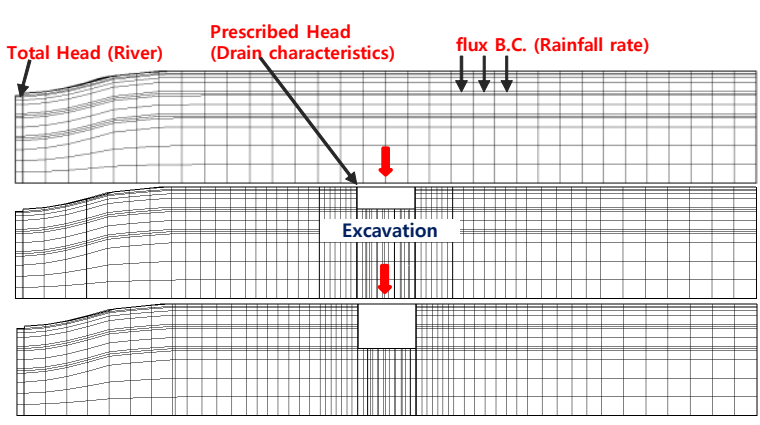

(b)

Fig. 2 Boundary condition of scenario in Case 1; (a) 3D view, (b) section.

The grid of Case 2 was separated into 32,425 nodes and 57,514 prisms before excavation and node and prism in excavation zone were eliminated to simulate the effect by excavation. Accordingly, the grid after excavation comprises of 32,425 nodes and 57,298 prisms. Boundary condition was set as General head boundary to both Case 1 and Case 2 in consideration of the river in the south and north of simulation zone and a no-flow boundary was set in the east and west of simulation zone (Fig. 2 \& 3) To induce the groundwater flow in model, the head of EL 34m in the north and EL $24 \mathrm{~m}$ in the south was applied and a 10-year average rainfall in Korea was applied as the variable boundary in upper part of simulation zone. When it comes to excavation surface, general head boundary was set in consideration of excavation depth and a complete cutoff concept was applied in some time after excavation. That is, it's assumed that a uniform flow before excavation and groundwater leakage from excavation surface after excavation and cutoff to prevent the leak after a certain period.

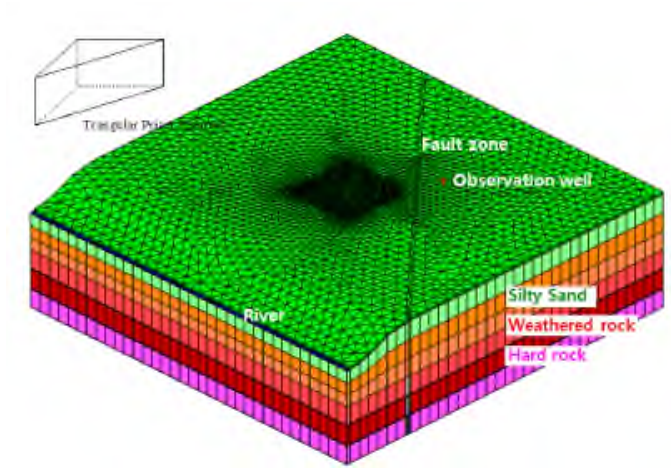

(a)

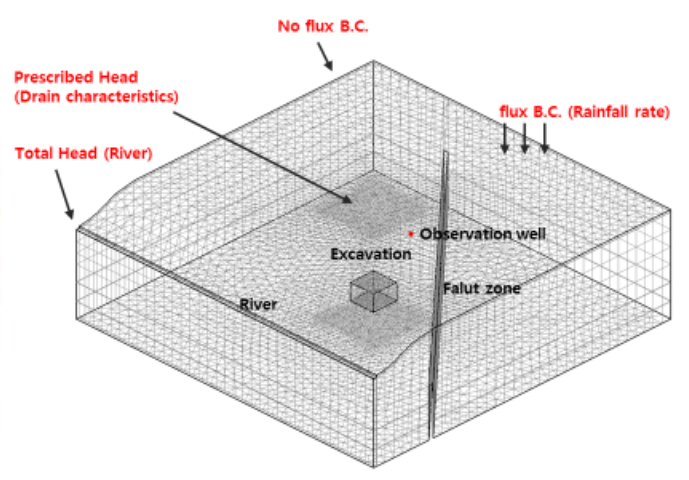

(b)

Fig. 3 Conceptual model of cavity excavation scenario considering geological characteristics

(Case 2) (a) grid and layer; (b) boundary condition

\section{Conclusions}

Groundwater flow analysis was conducted according to the excavation scenario by incorporating the geological characteristic as well as using the developed model (SEEFLOW3D). In case of a $10 \mathrm{~m}$ excavation (EL 25m) in Case 1, groundwater flow modeling was conducted for model zone in which the nodes and prisms of excavation zone $(40 \mathrm{~m} \times 40 \mathrm{~m} \times 10 \mathrm{~m})$ were eliminated. Duration for $10 \mathrm{~m}$ excavation was assumed to be 50 days and uniform flow before excavation, 50 days after excavation and 1000 days for cutoff step. To set the boundary condition in excavation zone by step, head data in previous step was used as initial head in following step. 
Fig. 4(a) shows the simulation result by step of a 10m excavation in Case 1 in distribution of total head and flow vector. As a result, total head before excavation was formed by initial boundary condition to $24 \sim 34 \mathrm{~m}$, north to south. Total head after excavation was distributed to $24 \sim 34 \mathrm{~m}$, but in excavation zone, groundwater level was lowered because of leakage on excavation surface during constriction duration (50days) and groundwater level was reduced by $6.6 \mathrm{~m}$ but after a complete cutoff, total head was recovered to the level before excavation. When it comes to a $20 \mathrm{~m}$ excavation (El 15m) in Case 1, groundwater modeling was conducted in model zone after eliminating the nodes and prisms in excavation zone $(40 \mathrm{~m} \times 40 \mathrm{~m} \times 20 \mathrm{~m})$ and construction duration for a $20 \mathrm{~m}$ excavation was assumed to be 100 days and for simulation time by step, it's assumed as uniform flow before excavation, 100 days after excavation and 1000 days for cutoff step.

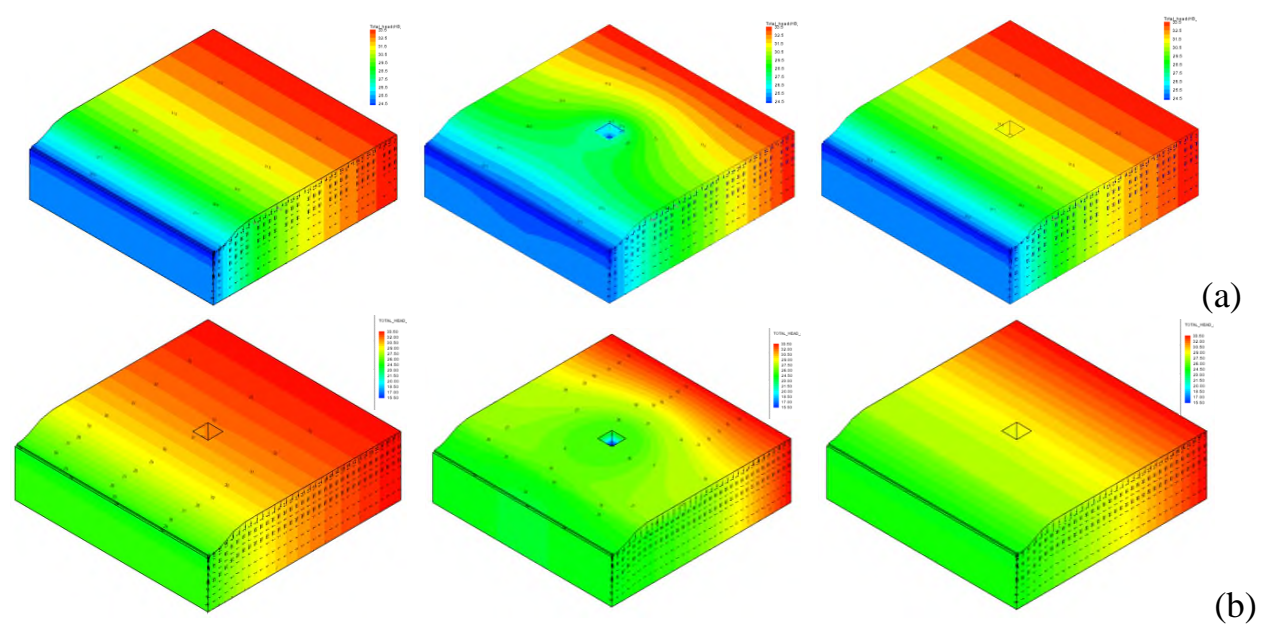

Fig. 4 Distribution of total head and flow vector according to simulation in Case 1

((a) $10 \mathrm{~m}$ excavation and (b) $20 \mathrm{~m}$ excavation); before excavation/ after excavation/ cutoff.

It shows the simulation result by step of a 20m excavation in Case 1 in distribution of total head and flow vector (Fig. 4(b)). As a result, total head before excavation was formed by initial boundary condition to $24 \sim 34 \mathrm{~m}$, north to south. Total head after excavation was distributed to $15 \sim 34 \mathrm{~m}$, but in excavation zone, groundwater level (total head) was $15 \mathrm{~m}$ because of leakage on excavation surface during constriction duration (100 days) and groundwater level was reduced by $16.3 \mathrm{~m}$ but after a complete cutoff, total head was recovered to the level before excavation. Fig. 5 shows the simulation result of Case 1 by excavation step in distribution of pressure head and flow vector on vertical section at the center of excavation zone. Blue surface on top of model zone in Fig refers to groundwater level (pressure head $=0 \mathrm{~m}$ ) Groundwater level was formed by boundary condition before excavation and groundwater leakage from the surface lowered the groundwater level during excavation. Groundwater leakage was prevented by cutoff and the groundwater level was recovered. As seen, data on permeability of cutoff wall could be obtained by evaluating the leakage from the excavation surface during excavation.

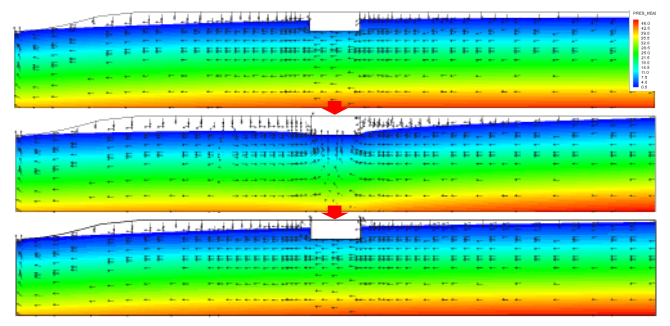

(a)

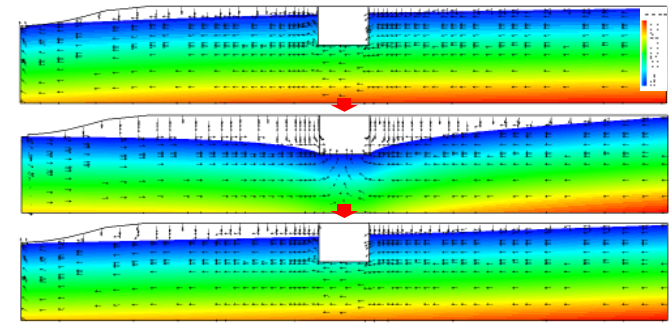

(b)

Fig. 5 Distribution of pressure head and flow vector (vertical section at the center of excavation zone) depending on simulation by step in Case 1 (before excavation, after excavation, cutoff);

(a) $10 \mathrm{~m}$ excavation, (b) $20 \mathrm{~m}$ excavation. 
When it comes to cavity excavation $(\mathrm{El}-15 \mathrm{~m} \sim-5 \mathrm{~m})$ in Case 2, groundwater flow modeling was conducted in model zone after eliminating the nodes and prisms in excavation zone $(40 \mathrm{~m} \mathrm{x} 40 \mathrm{~m} \mathrm{x}$ $10 \mathrm{~m}$ ) and construction duration for a cavity excavation was assumed to be 100 days and for simulation time by step, it's assumed as uniform flow before excavation, 100 days after excavation and 1000 days for cutoff step and the total head after excavation at EL 0m. Fig. 6 shows the simulation result by step of Case 2 in distribution of total head and flow vector. As a result, total head before excavation was formed by initial boundary condition to $24 \sim 34 \mathrm{~m}$, north to south. Total head after excavation was distributed to $0 \sim 34 \mathrm{~m}$, but in excavation zone, groundwater level (total head) was $0 \mathrm{~m}$ because of leakage on excavation surface during constriction duration (100 days) and groundwater level was reduced by $30.4 \mathrm{~m}$ but after a complete cutoff, total head was recovered to the level before excavation. In case of cavity excavation, it's necessary to conduct the analysis after setting the flux boundary on boundary surface together with general head boundary.

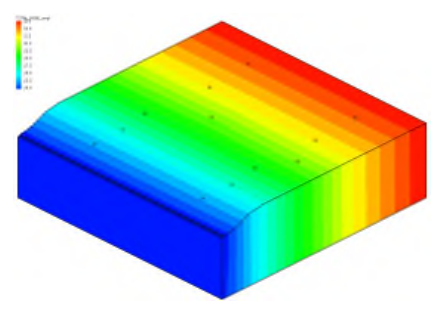

(a)

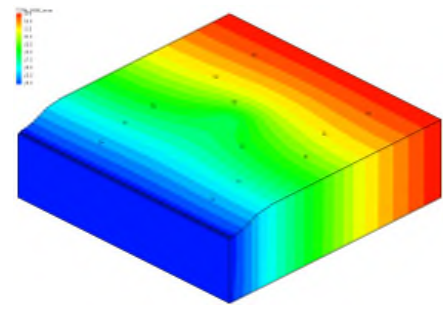

(b)

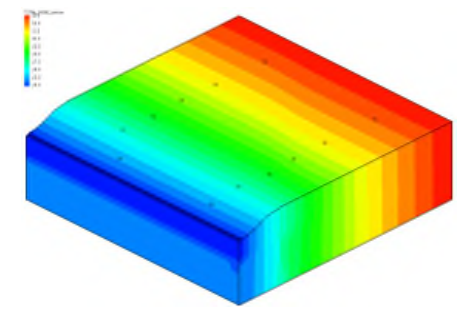

(c)

Fig. 6 Distribution of total head depending on simulation result of cavity excavation (Case 2) ; (a) before excavation, (b) after excavation, (c) cutoff.

\section{Acknowledgement}

This research was supported by the Korea Agency for Infrastructure Technology Advancement under the Ministry of Land, Infrastructure and Transport of the Korean government. (Project Number: 16SCIP-B108153-02).

\section{References}

[1] S. K. Jeon, M. H. Koo, Y. J. Kim, I. O. Lang, Statistical analysis of aquifer characteristics using pumping test data of national groundwater monitoring wells for korea, J. Soil Groundwater Envir. 10(6) (2005) 32-44.

[2] DHI-WASY GmbH, DHI-WASY software FEFLOW: Finite element subsurface flow and transport simulation system, White Papers. DHI-WASY GmbH, Berlin, Germany, various pages, 2009.

[3] Van Genuchten, M. T., A closed-form equation for predicting the hydraulic conductivity of unsaturated soils. Soil Science Society of America Journal, 1980, 44, 892-898.

[4] H. C. Lin, D. R. Richards, G. T. Yeh, J. R. Cheng, H. P. Cheng, N. L. Jones, FEMWATER: A Three-Dimensional Finite Element Computer Model for Simulating Density-Dependent Flow and Transport in Variably Saturated Media, Report CHL-97-12, U. S. Army Corps of Engineers, 3909 halls Ferry Road, Vicksburg, MS39180-6199, 1997.

[5] G. T. Yeh, G. B. Huang, F. Zhang, H. P. Cheng, H. C. Lin, WASH123D: A numerical model of flow, thermal transport, and salinity, sediment, and water quality transport in WAterSHed systems of 1-D stream-river network, 2-D overland regime, and 3-D subsurface media, Technical report Submitted to US. EPA, Department of Civil and Environmental Engineering, University of Central Florida, 4000 Central Florida Blvd., Orlando, FL, 2005. 